\title{
Frequency and correlates of comorbid depression in polycystic ovary syndrome
}

\author{
A B M Kamrul-Hasan', Fatema Tuz Zahura Aalpona², Shahjada Selim ${ }^{3}$ \\ ${ }^{1}$ Department of Endocrinology, Mymensingh Medical College, Mymensingh, Bangladesh. \\ ${ }^{2}$ Outpatient Department (Gynae \& Obs), Mymensingh Medical College Hospital, Mymensingh, Bangladesh. \\ ${ }^{3}$ Department of Endocrinology, Bangabandhu Sheikh Mujib Medical University, Dhaka, Bangladesh
}

\section{Abstract}

Women with polycystic ovary syndrome (PCOS) often suffer from psychiatric comorbidities, including depression. Data on the prevalence of depression in Bangladeshi women with PCOS are currently lacking. In this cross-sectional study, conducted in a tertiary hospital of Bangladesh, we evaluated 200 newly diagnosed patients with PCOS aged 18-45 years and 200 otherwise healthy women without PCOS of similar age-group for the presence of depression and its predisposing factors. Depression was assessed by administering the PRIME-MD Patient Health Questionnaire (PHQ-9). PHQ-9 score $\geq 10$ was considered as the threshold for major depression, and a score $<5$ was labeled as no depression. The frequencies of major depression in PCOS and control groups were 51\% and 19\%, respectively. The women with PCOS had a 5.12-fold higher risk of major depression in comparison to the non-PCOS controls. PCOS subjects having prediabetes/diabetes had a higher risk of major depression than those with normal glucose tolerance, and those with hyperprolactinemia had a lower risk than those having normal prolactin levels. Age, marital status, obesity, hypertension, menstrual irregularity, hirsutism, acne, dyslipidemia, serum testosterone, and serum TSH levels had no significant influence on the presence of depression. Screening for depression should be done routinely in PCOS patients.

Keywords: pcos, depression, hyperandrogenism, insulin resistance, glucose intolerance

Correspondence: e-mail< rangassmc@gmail.com >.

ORCID: https://orcid.org/0000-0002-5681-6522

Copyright: This is an open-access article distributed under the terms of the Creative Commons Attribution License, which permits unrestricted use, distribution, and reproduction in any medium, provided the original author and source are credited (CC BY 4.0)

\section{Introduction}

Polycystic ovary syndrome (PCOS) is the most common endocrine disorder in women of reproductive age, with a prevalence of $6-10 \%$ in the western world (1). The reported prevalence of PCOS in the Indian subcontinent is as high as $22.5 \%$ (2). This heterogeneous androgen-excess disorder presents with different degrees of reproductive and metabolic dysfunctions; the wide range of symptoms includes menstrual irregularities, hirsutism, acne, subfertility, fall of scalp hair, weight gain, etc. (1). These symptoms and metabolic derangements may lead to anxiety, depression, impaired sexual functioning, and marital and social maladjustment (3). Recently, psychiatric comorbidities in PCOS and their impact on the quality of life have been the research focus. At least one psychiatric disorder among depression, anxiety, and bipolar disorder has been found in $56.9 \%$ of women with PCOS (4).

Depression is a common mental disorder and is one of the leading causes of disability worldwide. Globally, more than 300 million people of all ages suffer from depression (5). Varying prevalence of depression ranging from $11 \%$ to $40 \%$ has been reported in PCOS women by researchers from different parts of the world $(4,6,7,8,9,10)$. The prevalence of depression was found higher in PCOS women in comparison to their healthy counterparts in previous researches ${ }^{(4,8,9)}$. Data on the prevalence of depression in Bangladeshi PCOS women are currently lacking. The current study was conducted to fulfill this gap. 


\section{Methods}

Following approval of the institutional review board of the hospital, this comparative cross-sectional study was conducted in the Endocrinology outpatient department (OPD) of Mymensingh Medical College Hospital, Bangladesh, from January to December 2018. Assuming the prevalence of PCOS $25 \%$, the confidence level of $95 \%$, and $5 \%$ margin of error, the estimated sample size was 289. For financial and resource constraints, 200 newly diagnosed PCOS patients aged 18-45 years diagnosed as per Revised Rotterdam criteria were included in this study (11). Another 200 otherwise healthy females of the same age group having no clinical features of PCOS recruited from the patients' attendants were included in the comparison group. Samples were collected by a convenient sampling technique. Women who are already diagnosed as having a mental illness and/or taking any psychotropic medications and those having any acute or chronic debilitating illness were excluded. After taking informed written consent, all patients were interviewed and examined for relevant clinical information. Anthropometric measurements were done for all. Obesity status was determined by body mass index (BMI) categories applicable to the Asian Indians (12). Subjects with waist circumference $\geq 80 \mathrm{~cm}$ were considered to have abdominal obesity; metabolic syndrome was diagnosed by using the International Diabetes Federation (IDF) criteria applicable for South Asian women (13). Hypertension and pre-hypertension were defined according to the Joint National Committee VII criteria (14).

Venous blood was collected in the fasting state from each of the participants for biochemical and hormonal analysis. The biochemical analysis included a standard oral glucose tolerance test (OGTT) and interpreted according to the American Diabetes Association guideline (15). Plasma glucose and serum lipids were measured by fully Automated Biochemistry Analyzer MINDRAY BS-380 (Shenzhen 518057, P. R. China). Serum testosterone, prolactin, and thyroid-stimulating hormone (TSH) were measured by radioimmunoassay (RIA) and interpreted according to the corresponding laboratory's reference ranges.
Depression scoring system:

Depression was assessed in patients and controls by administering the Bangla (local language) version of the PRIME-MD Patient Health Questionnaire (PHQ-9) (16). The PHQ-9 has been validated in the Indian population and is considered to be a reliable tool for the diagnosis of depression (17). The PHQ-9 is used to make a provisional diagnosis of depressive disorder as well as it provides a severity score for depressive disorder (16,18). For the diagnosis of depression, score $\geq 20$ was classified as severe depression, score 15-19 moderately severe depression, score 10-14 moderate depression, score 5-9 mild depression, and a score below 5 (0-4) as no depression. Therefore, a patient obtaining a score of 5 or more was labeled to have depression (16,18). PHQ-9 score $\geq 10$ is found to have a sensitivity of $88 \%$ and a specificity of $88 \%$ for major depression (18).

\section{Statistical analysis:}

Statistical analysis was done using Statistical Packages for Social Sciences (SPSS), version 23.0 software (IBM Corp. Released 2015. IBM SPSS Statistics for Windows, Version 23.0, Armonk, NY: IBM Corp.). The categorical variables were represented as percentages and measurable variables as mean $\pm \mathrm{SD}$ and/or median. Student's $t$-test, Chi-square test, and non-parametric tests were performed for comparing the variables between different groups as appropriate. Binary logistic regression analysis was performed to find out the odds ratios for the risk factors of depression in the study population. P-value $\leq 0.05$ was considered to be statistically significant.

\section{Results}

The demographic and clinical characteristics of the study subjects are shown in Table 1 . The mean age and systolic blood pressure (BP) were lower in the PCOS group than controls. Women with PCOS had higher BMI, waist circumference, and PHQ-9 score in comparison to nonPCOS controls. PCOS group had higher proportions of unmarried and abdominally obese subjects. The frequency of depression was $80 \%$ and $34 \%$ in PCOS and control group, respectively. The major depressive illness that is considered to be clinically significant was present in 51\% of PCOS and $19 \%$ of the control subjects. 


\section{Table 1 General characteristics of the study subjects}

\begin{tabular}{|c|c|c|c|c|}
\hline Variables & Sub-groups & $\begin{array}{c}\text { PCOS } \\
(n=200) \\
\text { mean } \pm \text { SD or } \%\end{array}$ & $\begin{array}{c}\text { Control } \\
(n=200) \\
\text { mean } \pm S D \text { or } \%\end{array}$ & $\mathrm{p}$ \\
\hline Age (years) & & $22.55 \pm 4.89$ & $28.92 \pm 3.89$ & $<0.001$ \\
\hline \multirow[t]{2}{*}{ Marital status } & Married & $78(39 \%)$ & $187(93.5 \%)$ & $<0.001$ \\
\hline & Unmarried & $122(61 \%)$ & $13(6.5 \%)$ & \\
\hline $\mathrm{BMI}\left(\mathrm{Kg} / \mathrm{M}^{2}\right)$ & & $26.67 \pm 5.15$ & $23.98 \pm 4.72$ & $<0.001$ \\
\hline \multirow[t]{2}{*}{ BMI category } & $<23$ & $48(24 \%)$ & $90(45 \%)$ & $<0.001$ \\
\hline & $\geq 23$ & $152(76 \%)$ & $110(55 \%)$ & \\
\hline Waist circumference $(\mathrm{cm})$ & & $88.50 \pm 11.75$ & $82.04 \pm 8.12$ & $<0.001$ \\
\hline \multirow[t]{2}{*}{ Abdominal obesity } & Present & $157(78.5 \%)$ & $106(53 \%)$ & $<0.001$ \\
\hline & Absent & $43(21.5 \%)$ & $94(47 \%)$ & \\
\hline Systolic BP (mmHg) & & $116 \pm 13$ & $124 \pm 16$ & $<0.001$ \\
\hline Diastolic BP (mmHg) & & $76 \pm 9$ & $77 \pm 7$ & 0.849 \\
\hline \multirow[t]{3}{*}{ BP category } & Normotensive & $138(69 \%)$ & $136(68 \%)$ & 0.858 \\
\hline & Pre-hypertensive & $44(22 \%)$ & $48(24 \%)$ & \\
\hline & Hypertensive & $18(9 \%)$ & $16(8 \%)$ & \\
\hline PHQ-9 score (median) & & 10 & 2 & $<0.001$ \\
\hline \multirow[t]{2}{*}{ Depression presence } & Absent & $40(20 \%)$ & $132(66 \%)$ & $<0.001$ \\
\hline & Present & $160(80 \%)$ & $68(34 \%)$ & \\
\hline \multirow[t]{4}{*}{ Depression severity } & Mild & $58(29 \%)$ & $30(15 \%)$ & $<0.001$ \\
\hline & Moderate & $58(29 \%)$ & $24(12 \%)$ & \\
\hline & Moderately Severe & $29(14.5 \%)$ & $13(6.5 \%)$ & \\
\hline & Severe & $15(7.5 \%)$ & $1(0.5 \%)$ & \\
\hline
\end{tabular}

(Within parentheses are percentages over column total)

(p-value by Student's $t$-test, Chi-square test or non-parametric test as applicable)

Table 2 presents the odds ratios of variables for the presence of depression in study subjects (PCOS and controls) obtained by binary logistic regression analysis adjusting for possible confounders. The PCOS patients had a 5.12-fold higher risk of major depression in comparison to their non-PCOS healthy counterparts.

\section{Table 2 Binary logistic regression for the predictors of major depression (PHQ- \\ 9 score $\geq 10)$ in study subjects $(N=400)$}

\begin{tabular}{lcccc}
\hline Variables & Sub-groups & $\begin{array}{c}\text { No. of subjects in } \\
\text { subgroup }(\mathbf{n})\end{array}$ & Odds Ratio (95\% CI) & $\mathbf{p}$ \\
\hline Subject category & Controls & 200 & Referent & \\
& PCOS & 200 & $5.12(2.62-9.98)$ & $<0.001$ \\
Age Group & $<25$ years & 142 & Referent & 0.606 \\
\hline
\end{tabular}




\begin{tabular}{lcccc}
\hline Marital Status & Unmarried & 135 & Referent & \\
& Married & 265 & $1.14(0.63-2-.06)$ & 0.670 \\
BMI & $<23$ & 138 & Referent & 0.502 \\
& $\geq 23$ & 262 & $0.78(0.38-1.60)$ & 0.162 \\
Abdominal obesity & Absent & 137 & Referent & $1.69(0.81-3.51)$ \\
BP category & Present & 263 & Referent & 0.176 \\
& Normal & 274 & $1.39(0.86-2.25)$ & \\
\hline
\end{tabular}

\section{Table 3 Binary logistic regression for the predictors of major depression (PHQ- 9 score $\geq 10)$ in PCOS women $(n=200)$}

\begin{tabular}{|c|c|c|c|c|}
\hline Variables & Subgroups & $\begin{array}{l}\text { No. of subjects in } \\
\text { subgroup (n) }\end{array}$ & Odds Ratio (95\% CI) & $\mathrm{p}$ \\
\hline \multirow[t]{2}{*}{ Menstrual cycle } & Regular & 13 & Referent & \\
\hline & Irregular & 187 & $1.29(0.37-4.52)$ & 0.684 \\
\hline \multirow[t]{2}{*}{ Hirsutism } & Absent & 50 & Referent & \\
\hline & Present & 150 & $1.00(0.49-2.04)$ & 0.996 \\
\hline \multirow[t]{2}{*}{ Acne } & Absent & 157 & Referent & \\
\hline & Present & 43 & $0.94(0.46-1.93)$ & 0.870 \\
\hline \multirow[t]{2}{*}{$\mathrm{H} / \mathrm{O}$ weight gain } & Absent & 73 & Referent & \\
\hline & Present & 127 & $1.22(0.62-2.41)$ & 0.567 \\
\hline \multirow[t]{2}{*}{ Subfertility $\left(\mathrm{n}=78^{*}\right)$} & Absent & 48 & Referent & \\
\hline & Present & 30 & $1.46(0.57-3.72)$ & 0.426 \\
\hline \multirow[t]{2}{*}{ Acanthosis nigricans } & Absent & 48 & Referent & \\
\hline & Present & 152 & $0.92(0.42-2.04)$ & 0.838 \\
\hline \multirow[t]{2}{*}{ Glycemic status } & NGT & 157 & Referent & \\
\hline & AGT & 43 & $2.73(1.08-5.21)$ & 0.031 \\
\hline \multirow[t]{2}{*}{ Dyslipidemia } & Absent & 24 & Referent & \\
\hline & Present & 176 & $2.14(0.80-5.70)$ & 0.128 \\
\hline \multirow[t]{2}{*}{ Metabolic syndrome } & Absent & 110 & Referent & \\
\hline & Present & 90 & $1.36(0.71-2.62)$ & 0.354 \\
\hline \multirow[t]{2}{*}{ S. Testosterone } & Normal & 145 & Referent & \\
\hline & Elevated & 55 & $1.36(0.69-2.66)$ & 0.376 \\
\hline \multirow[t]{2}{*}{ S. Prolactin } & Normal & 173 & Referent & \\
\hline & Elevated & 27 & $0.38(0.15-0.97)$ & 0.043 \\
\hline \multirow[t]{2}{*}{ S. TSH } & $\leq 5.0 \mu \mathrm{IU} / \mathrm{mL}$ & 167 & Referent & \\
\hline & $>5.0 \mu \mathrm{IU} / \mathrm{mL}$ & 33 & $0.93(0.41-2.11)$ & 0.859 \\
\hline
\end{tabular}

*in married subjects only; NGT $=$ Normal glucose tolerance; AGT $=$ Abnormal glucose tolerance

Table 3 presents the odds ratios of the factors related to PCOS for the presence of depression in PCOS women obtained by binary logistic regression analysis adjusting for possible confounders. PCOS subjects with abnormal 
glucose tolerance (prediabetes/diabetes) had a 2.73-fold higher risk of major depression than those with normal glucose tolerance, and those with hyperprolactinemia had a 0.38 -fold lower risk than those having normal prolactin levels.

\section{Discussion}

The current study evaluated 200 PCOS women and another 200 healthy controls for the presence, severity, and contributing factors of depression. The frequency of depression among PCOS women very high (80\%), and this was higher than that observed in non-PCOS controls (34\%). More than half $(51 \%)$ of the PCOS women were found to have major depression (PHQ-9 score $\geq 10$ ). The PCOS women had a 5.12-fold higher risk of major depression in comparison to the controls. PCOS women having prediabetes/diabetes had a higher risk of major depression than those with NGT, and those with hyperprolactinemia had a lower risk than those having normal prolactin levels.

Though the underlying mechanisms of the relationship between PCOS and depression remain poorly understood, numerous possible explanations have been provided for the result regarding the increased risk of depressive disorder in PCOS patients. Visible features of PCOS, such as hirsutism, acne, alopecia, as well as potential reproductive consequences such as menstrual irregularity, and subfertility can be deeply stigmatizing to women (19). In a study, the PCOS women described the subjective experience of the disease as feeling robbed of their selfconcept, the essence of being feminine and attractive, thus making PCOS, as the "thief of womanhood" (20). A link between hyperandrogenism and depression among women with PCOS also has been proposed (21). Insulin resistance and obesity are common in patients with PCOS. Insulin-resistance related comorbidities, including hypertension, type 2 diabetes, and dyslipidemia, have been noted to be related to depressive symptoms $(4,21,22)$.

Several studies have confirmed that depression is a common comorbidity in patients with PCOS through the reported prevalence varied greatly $(4,6,7,8,9,10)$. Kerchner et al. found $40 \%$ of PCOS women to have depression, whereas the frequency was $18.9 \%$ in the study done by SayyahMelli et al. (6,8). The prevalence of depression in PCOS women was $11-50 \%$ in the studies done in India $(7,9,10)$. In a follow-up study, the incidence of the new diagnosis of depression diagnosed by psychiatrists was higher in PCOS women $(2.93 \%)$ than non-PCOS controls (2.26\%) (4). These studies also revealed a higher prevalence of depression among PCOS women than non-PCOS controls. The variable frequencies of depression observed among the PCOS worldwide can be explained by the fact that different methods and tools used for screening and diagnosing and the influence of culture on the epidemiology of depression (23). Though the overall frequency of depression was higher in the current study, the frequency of major depression was almost similar to previous studies.

This study identified dysglycemia as an independent risk for depression in PCOS women [odds ratio 2.73 (CI: 1.085.21)]. Compared with the nondepressed subjects with PCOS, the depressed subjects with PCOS had greater evidence of insulin resistance in previous studies (6). Glucose intolerance, dyslipidemia, and metabolic syndrome, all of which are the results of insulin resistance may contribute to depression in PCOS (4). PCOS subjects with hyperprolactinemia had lower risks of depression in the current study [odds ratio 0.38 (CI: 0.15-0.97)]. No previous studies evaluated the role of serum prolactin levels on depression.

The contributing factors of depression in PCOS have been investigated by many researchers. Barry et al. observed that younger women with PCOS were less depressed than older women with PCOS (24). Being unmarried is an independent predictor of depression, according to a previous study (26). Some studies found depression to be associated with higher BMI, and waistto-hip ratio in women with PCOS through others did not found such associations (3,6,24,25). The presence of HTN was also a risk factor of depression in the Bangladeshi population(26). Some studies identified menstrual irregularities as a contributing factor to depression in PCOS (24). According to the findings of Açmaz et al., the actual determinants of depression were infertility and hirsutism (27). Among PCOS women, Chaudhari et al. found higher risks of depression in PCOS subjects with acne than those without acne (7). There is conflicting evidence on the effect of serum androgen levels with depression in PCOS (6,24). Though the effect of serum TSH level on presence and severity of depression in PCOS patients is not evaluated yet, Bauer et al. showed that TSH levels in hypothyroidism correlated with the severity of depression (28).

The present study found no significant differences in the risk of depression among lower and higher age groups, married and unmarried women, normal-weight and overweight/obese women, and among normotensive and hypertensive women.

This study has some limitations. The sample size was small, and it was a single-center study; the sample may not represent the whole country. The Bangla version of the 
PHQ-9 Questionnaire was not validated in the study population. The healthy comparison group was not matched for age, marital status, and obesity status. Nevertheless, this one is the first study in Bangladesh investigating depression in PCOS and may serve as the basis for further large-scale, multi-center study in this subject.

\section{Conclusion}

A very high frequency of depression was observed in PCOS subjects, and they had a higher risk of depression than non-PCOS controls. Glucose intolerance and a normal prolactin level were found to be the independent predictors of depression in PCOS. Screening for depression should be done routinely in PCOS patients.

\section{Acknowledgments}

We are thankful to the study participants for making the study possible. We acknowledge the endocrine residents of this hospital for their help in data collection.

\section{Conflict of interest}

None

\section{References}

1. Fauser BC, Tarlatzis BC, Rebar RW, Legro RS, Balen AH, Lobo R, et al. Consensus on women's health aspects of polycystic ovary syndrome (PCOS): the Amsterdam ESHRE/ASRM-Sponsored 3rd PCOS Consensus Workshop Group. Fertil Steril. 2012;97(1):28-38. DOI: 10.1016/j.fertnstert.2011.09.024

2. Malik S, Jain K, Talwar P, Prasad S, Dhorepatil B, Gouri Devi. Management of polycystic ovary syndrome in India. Fertil Sci Res. 2014;1(1):23-43. DOI: 10.4103/2394-4285.146798

3. Hahn S, Janssen OE, Tan S, Pleger K, Mann K, Chedlowski M, et al. Clinical and psychological correlates of quality-of-life in polycystic ovary syndrome. Euro J Endocrinol. 2005;153(6):853-60. DOI: 10.1530/eje.1.02024

4. Hung JH, Hu LY, Tsai SJ, Yang AC, Huang MW, Chen PM, et al. Risk of Psychiatric Disorders following Polycystic Ovary Syndrome: A Nationwide Population-Based Cohort Study. PLoS ONE. 2014;9(5):e97041. DOI: 10.1371/journal.pone.0097041

5. www.who.int [Internet]. Geneva: World Health Organization news room. [Updated 2018 Mar 22; cited 2019 Jun 11]. Available from: http://www.who.int/news-room/fact sheets/detail/depression/.

6. Kerchner A, Lester W, Stuart SP, Dokras A. Risk of depression and other mental health disorders in women with polycystic ovary syndrome: a longitudinal study. Fertil Steril. 2009;91(1):207-12. DOI: 10.1016/j.fertnstert.2007.11.022

7. Chaudhari AP, Mazumdar K, Mehta PD. Anxiety, Depression, and Quality of Life in Women with Polycystic Ovarian Syndrome. Indian J Psychol Med. 2018;40(3):239-46. DOI: 10.4103/IJPSYM.IJPSYM_561_17

8. Sayyah-Melli M, Alizadeh M, Pourafkary N, Ouladsahebmadarek E, Jafari-Shobeiri M, Abbassi J, et al. Psychosocial Factors Associated with Polycystic Ovary Syndrome: a Case Control Study. J Caring Sci. 2015;4(3):225-31. DOI: 10.15171/jcs.2015.023

9. Hussain A, Chandel RK, Ganie MA, Dar MA, Rather YH, Wani ZA, et al. Prevalence of psychiatric disorders in patients with a diagnosis of polycystic ovary syndrome in Kashmir. Indian J Psychol Med. 2015;37(1):66-70. DOI: 10.4103/02537176.150822

10. Upadhyaya SK, Sharma A, Agrawal A. Prevalence of anxiety and depression in polycystic ovarian syndrome. Int J Med Sci Public Health. 2016;5(4):681-83. DOI: 10.5455/ijmsph.2016.30072015110

11. Rotterdam ESHRE/ASRM-Sponsored PCOS Consensus Workshop Group. Revised 2003 consensus on diagnostic criteria and long-term health risks related to polycystic ovary syndrome (PCOS). Hum Reprod. 2004;19(1):41-7. DOI: 10.1093/humrep/deh098

12. WHO expert consultation. Appropriate body-mass index for Asian populations and its implications for policy and intervention strategies. The Lancet. 2004;363(9403):157-63. DOI: 10.1016/S0140-6736(03)15268-3

13. The IDF consensus worldwide definition of metabolic syndrome. Guideline for definition of the metabolic syndrome. International Diabetes Federation. 2006. 
14. Chobanian AV, Bakris GL, Black HR, Cushman WC, Green LA, Izzo JL Jr, et al. The Seventh Report of the Joint National Committee on Prevention, Detection, Evaluation and Treatment of High Blood Pressure: the JNC 7 report. JAMA. 2003;289(19):2560-72. DOI: 10.1001/jama.289.19.2560

15. American Diabetes Association. 2. Classification and diagnosis of diabetes: Standards of Medical Care in Diabetes 2019. Diabetes Care. 2019;42(Suppl. 1):S13-28. DOI: 10.2337/dc19-sppc01

16. Spitzer RL, Kroenke K, Williams JB. Validation and utility of a self-report version of PRIME-MD: The PHQ primary care study. Primary care evaluation of mental disorders. Patient health questionnaire. JAMA. 1999;282(18):1737-44. DOI: 10.1001/jama.282.18.1737

17. Kochhar PH, Rajadhyaksha SS, Suvarna VR. Translation and validation of brief patients health questionnaire against DSM IV as a tool to diagnose major depressive disorder in Indian patients. J Postgrad Med. 2007;53(2):102-7. DOI: 10.4103/00223859.32209

18. Kroenke K, Spitzer RL, Williams JBW. The PHQ-9: validity of a brief depression severity measure. J Gen Intern Med. 2001;16(9):606-13. DOI: 10.1046/j.1525-1497.2001.016009606.x

19. Veltman-Verhulst SM, Boivin J, Eijkemans MJ, Fauser BJ. Emotional distress is a common risk in women with polycystic ovary syndrome: a systematic review and meta-analysis of 28 studies. Hum Reprod Update. 2012;18(6):638-51. DOI: 10.1093/humupd/dms029

20. Kitzinger C, Willmott J. “The thief of womanhood': women's experience of polycystic ovarian syndrome," Social Science and Medicine. 2002;54(3):349-61. DOI: 10.1016/S0277-9536(01)00034-X

21. Annagur BB, Tazegul A, Uguz F, Kerimoglu OS, Tekinarslan E, Celik Ç. Biological correlates of major depression and generalized anxiety disorder in women with polycystic ovary syndrome. J Psychosom Res. 2013;74:244-7. DOI: 10.1016/j.jpsychores.2013.01.002

22. Pan A, Ye X, Franco OH, Li H, Yu Z, Zou S, et al. Insulin resistance and depressive symptoms in middle-aged and elderly Chinese: findings from the Nutrition and Health of Aging Population in China Study. J Affect Disord. 2008;109:75-82. DOI: 10.1016/j.jad.2007.11.002

23. Sen B, Mari JJ. Psychiatric research instruments in the transcultural setting: Experiences in India and Brazil. Soc Sci Med. 1986;23:277-81. DOI: 10.1016/0277-9536(86)90348-5

24. Barry JA, Kuczmierczyk AR, Hardiman PJ. Anxiety and depression in polycystic ovary syndrome: a systematic review and meta-analysis. Hum Reprod. 2011;26(9):2442-51. DOI: 10.1093/humrep/der197

25. Jedel E, Waern M, Gustafson D, Landén M, Eriksson E, Holm G, et al. Anxiety and depression symptoms in women with polycystic ovary syndrome compared with controls matched for body mass index. Hum Reprod. 2010;25(2):450-6. DOI: 10.1093/humrep/dep384

26. Kamrul-Hasan AB, Palash-Molla M, Mainul-Ahsan M, Gaffar AJ, Asaduzzaman M, Saifuddin M, et al. Prevalence and Predictors of Depression among Patients with Type 2 Diabetes: A Multicenter Cross-sectional Study from Bangladesh. Mymensingh Med J. 2019;28(1):23-30. PMID: 30755546

27. Açmaz G, Albayrak E, Acmaz B, Başer M, Soyak M, Zararsız G, et al. Level of anxiety, depression, self-esteem, social anxiety, and quality of life among the women with polycystic ovary syndrome. The Scientific World Journal. 2013;2013:851815. DOI: $10.1155 / 2013 / 851815$

28. Bauer M, Silverman DH, Schlagenhauf F, London ED, Geist CL, van Herle K, et al. J Clin Endocrinol Metab. 2009;94(8):2922-9. DOI: 10.1210/jc.2008-2235 